\title{
The Three-dimensional Construction and Innovation of the Elementary Machinery Course on the Printing and Packaging
}

\author{
Xiao-Gui Zhang ${ }^{\text {a }}$, Zi-Yuan Shib \\ Department of Mechanical Engineering, Beijing Institute of Graphic Communication, Beijing, China \\ azxiaogui@163.com, bshi ziyuan@bigc.edu.cn
}

Keywords: Mechanical engineering, Curricula construction, Teaching contents, Practice teaching.

\begin{abstract}
The course of engineering drawing and mechanical design is a subject which is based on the course of printing and packaging engineering. It can provide the necessary professional knowledge platform for the further study. According to the requirements of the subject development and professional characteristics, in the teaching practice, the paper has carried on the three-dimensional construction of the curriculum. In the teaching system, teaching content, teaching methods, teaching methods and practical teaching, the article has carried on the thorough discussion and the practice.
\end{abstract}

\section{Introduction}

"Engineering Drawin”, "Basic Mechanical Design” and other mechanical base courses in printing, packaging engineering professional training plan has always occupied an important position and role, but with the demand for educational reform and disciplines, and to integrate the "engineering drawing and mechanical design basis". "Engineering graphics and mechanical design basis" is a basic compulsory course on the packaging engineering, printing engineering, which has the system theory and the strong practicality. As a technology foundation courses with the "professional import" characteristics, this course can cultivate students the ability of reading map, and the ability of application, analysis and selecting the basic mechanism and the parts in the different links of the mechanical design. This course is an important professional basic core (backbone) course, so that students can get the basic knowledge of correct management, use and maintenance of machinery.

Engineering drawing is mainly through the introduction of point, line, surface, body and a combination of the three plane projection and the methods of the mechanical expression, to read and draw simple parts and assembly drawings. And the mechanical design mainly describes the basic knowledge, basic theory, a simplified design method and the use and maintenance knowledge of the common mechanism and general machinery parts. How to make the students in the effective time, the better grasp of the course content and knowledge structure, which has the obvious difference and correlation, it brings the teaching some problems and difficulties. How cross integration of the teaching content of the course, to make it easier for students to understand and grasp, increasing interest in learning, improving teaching effect, so as to really achieve the teaching purpose of the course, is an important research topic placed in front of the teachers.

Through the printing engineering and packaging engineering professional "engineering drawing, mechanics, mechanical design based" the three-dimensional construction and research on teaching reform, breaking the course system teaching mode, strengthening the engineering quality and the experiment teaching, cultivating students innovation consciousness, thinking ability and practical ability, and building a good foundation of professional learning for the future.

\section{Reconstruction of curriculum system and restructuring of teaching content}

Based on the teaching content, the three-dimensional teaching construction of engineering drawing, mechanics, mechanical design basis, makes the different knowledge points to cross and fusion effectively. Combined with the actual situation of packaging engineering, printing engineering, the system integration of the course system and contents, optimizing the teaching content, strengthening the foundation and broadening the knowledge, it will introduce examples of engineering technology into the teaching. For example: standard parts such as thread and common mechanical parts (such as gear, etc.) of the painting in the engineering drawing, are combined with 
the structure of mechanical parts in the mechanical design basis to explain and introduce. The cross and integration makes the students understand the design method and the geometric size calculation method, and mastering the specific part's drawing, having certain systematic and continuity. Students are more likely to accept and understand. Another example: When explain the pressure angle and the transmission angle of the link mechanics, it involves the linkage force acting on the rocker and the concept of two force components in the mechanics. Through this case, students are introduced to some knowledge of Engineering Mechanics, to enable students to understand the definition and distinction of a double balance fore and two-force structural part. Also, for example: in the dead center of the mechanism to teach, involving the knowledge of the torque, through the examples, students can further understand the concept of the torque and the couple, like the integration of the teaching content, students can easily master, easy understanding and teaching effect is better. The distribution of the specific hours and contents are shown in table 1 .

Tab.1 the period distribution and integration of course contents

\begin{tabular}{|c|c|c|c|}
\hline & engineering drawing & $\begin{array}{c}\text { mechanical designing } \\
\text { basis }\end{array}$ & cross section \\
\hline $\begin{array}{c}\text { period } \\
\text { distribution }\end{array}$ & 24 & $\begin{array}{c}34 \text { (Containing 4 hours } \\
\text { experiment) }\end{array}$ & 6 \\
\hline $\begin{array}{c}\text { the fusion of the } \\
\text { content cross }\end{array}$ & $\begin{array}{c}\text { the prescribed drawing } \\
\text { of keys, pintle, thread } \\
\text { and threaded } \\
\text { connections }\end{array}$ & $\begin{array}{c}\text { the prescribed drawing of } \\
\text { gear and plate-parts }\end{array}$ & $\begin{array}{c}\text { the prescribed } \\
\text { drawing of rolling } \\
\text { bearing }\end{array}$ \\
\hline
\end{tabular}

\section{Actively adopt reasonable teaching method and teaching means.}

In teaching methods, use the heuristic teaching, case teaching, and focus on the link and interconnection of the knowledge points. For example: when talking about the "dead" concept of the mechanism, first propose to think: "why aircraft landing gear can stably support during the landing, and on the wing of the plane in flight?". Actively guide students to think and seek solutions. After the students thinking, and then from the aspects of professional theory, we summarize to the disputed answers of the students, then putting forward the concept connotation of the "dead", and analyzing the instance of using and overcoming the "dead". It can inspire students' thinking, excavating students' potential, and deepen students' understanding of the relevant professional knowledge, and achieve good teaching effect .And as in the teaching of "gear mechanism pressure angle", with the "linkage mechanism pressure angle" and the "cam mechanism pressure angle", this paper compares and analyzes their similarities and differences between each other, to make the students understand the difference and their respective role in the process of mechanism motion. To explore a variety of media teaching in the teaching methods, collect and make the animation of the part course. At the same time, in the process of teaching, more attention to show various physical teaching. These teaching aids is visible, tangible entities, and is especially suitable for current students learning and teaching, increasing students' perceptual knowledge, guiding students, gradually increasing the interest in learning the mechanical knowledge. In the teaching process, pay attention to the introduction of knowledge, focusing on the teaching of the based case, combining with the needs of the follow-up professional learning, collection and production of a number materials of animation, pictures, process movements and other. Involving the machinery of metal transport, cutting machine tools, printing machinery, packaging machinery, post-press processing machinery, through a variety of different machines, improve the students' interest in learning, expand the student's field of vision, stimulate the learning enthusiasm, improve the teaching effect.

Part of the teaching content is tried to use the method of project teaching. The main characteristic of the project teaching is to avoid the traditional discipline system, and break the integrity and the system of the teaching knowledge. The requirement of knowledge structure in line with the principle of" good enough", emphasis on cultivating students' practice ability, the ability of independent access to information and the ability of independent construction of knowledge and innovation, enhance the flexibility of curriculum, modular and flexible curriculum system. Based on the following four figures. 


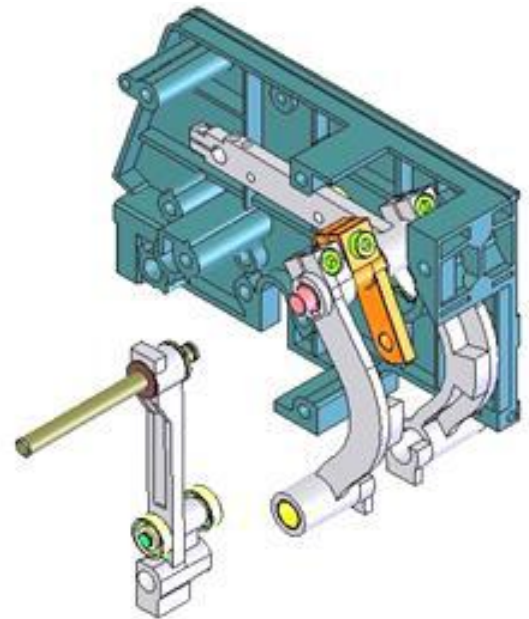

Fig.1 paper feed mechanism assembly of printing machines

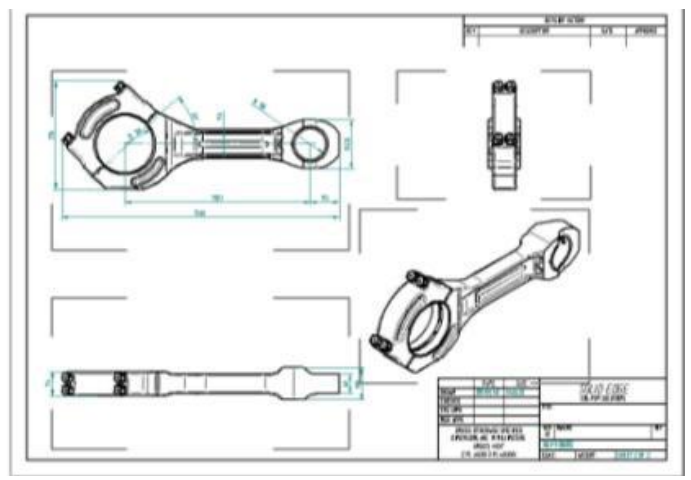

Fig.3 the express instance of the linkage assembly

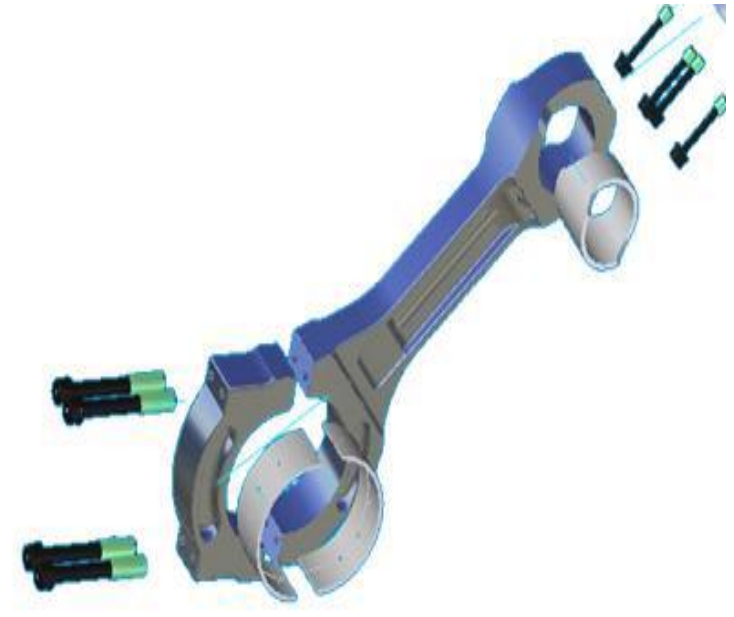

Fig.2 assembly model of the linkage

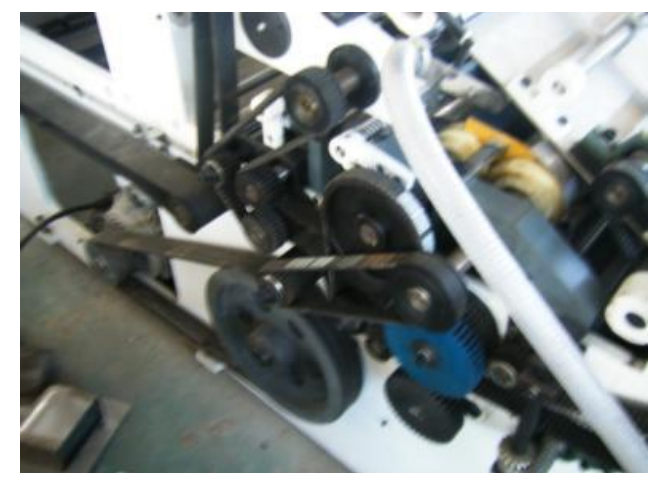

Fig.4 the physical picture of transmission system applications

The analysis of the project systematic study, it can improve the students' the ability of knowledge innovation and practice. In a typical project as a carrier, through the typical work project and analysis of these projects in what order to process problems, the reasonable course structure is formed. The students master related knowledge in the process of learning, task driven at the completion of specific project tasks in the form of project orientation, paying attention to the combination with the engineering practice at the same time. Given a number of design cases, the students have a preliminary understanding of the various related machinery, broaden the horizons of students, to lay a certain foundation for future study and work. At the same time, performance evaluation should be diversified in the teaching process. In the early stage of the engineering drawings, it mainly takes the way of the extra-class work, homework and other ways. The basis parts of mechanical design mainly include: homework, small paper, design questions and so on. As the students' daily learning state change, the time of the study and the results has been improved.

\section{Updating the teaching idea}

In the experimental teaching, constantly research and explore the new methods of experimental teaching, stimulate students' learning enthusiasm, improve the ability of the students' application and practice.In the process of reform, according to different levels of the experimental requirements we should take different experiment teaching methods.

For the design and comprehensive experiments, we develope the virtual experiment platform (Figure3).The simulation experiments are collected and the system is applied to the teaching experiment.The simulation system is very vivid and can effectively solve the problem of the experimental equipment and experimental space.It allows every student to have a "hands-on" opportunity,to enhance the experiment interest, beneficial to the student individuality development.The simulation system can complete the review and connection of the relevant knowledge.It can enhance the understanding of the related knowledge by the cognitive training of 
assembling parts,basic assembly skill training,and the training of assembly process.Experimental simulation system is a rapid test platform, through systematic training, to enable students to master the basic knowledge, and it laies a good foundation of the subject for students. Some students who are interested in machinery,can participate in teacher's scientific research and the study of college students, improving themselves practical ability.
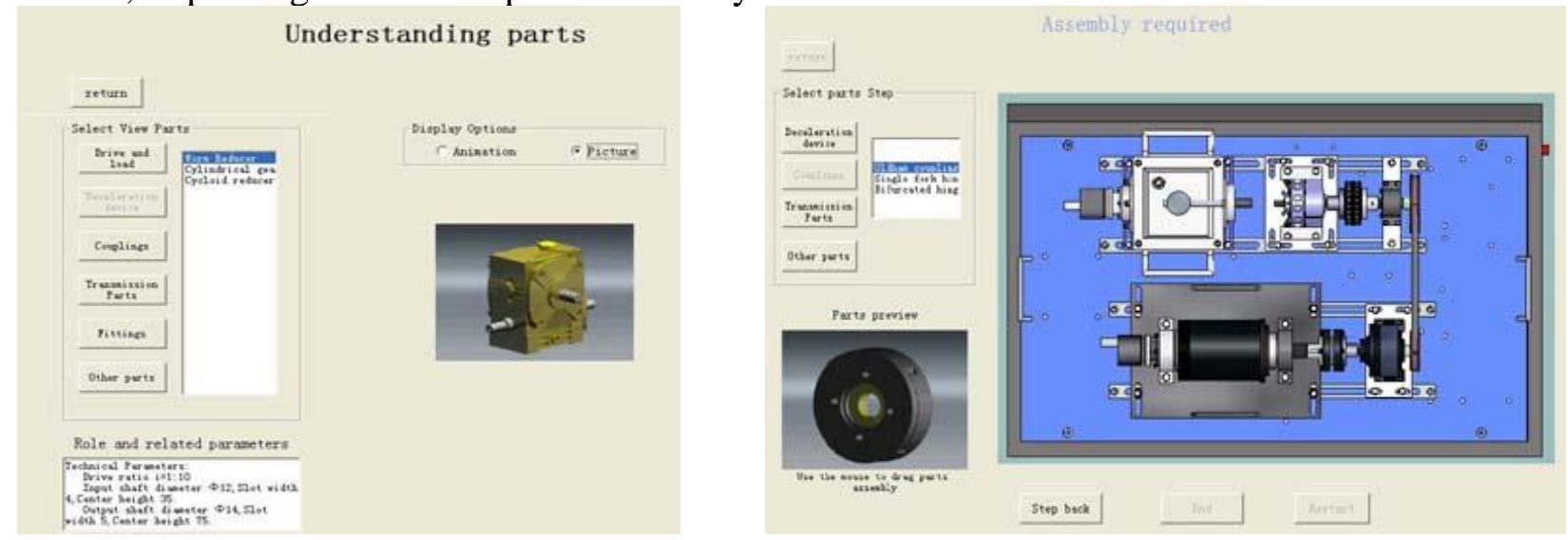

Fig.5 the developed virtual experiment platform interface

\section{Conclusions}

In the teaching process, the three-dimensional construction reform model of the trinity that the curriculum construction, the teaching process, examination mode is practiced. In the process of the implementation of the curriculum construction and reform, the reconstruction of course system and the reorganization of teaching content ensure the crossover and the depth fusion between courses. Diversification of teaching mode, teaching method and teaching means, the organic combination of classroom teaching, experiment teaching, extracurricular expand (homework, access to information, assignment, essay),operation, mutual promotion, stimulate the student to study interest and enthusiasm. The diversity flexible way of extra-curricular expanding, it makes the reading ability and comprehensive ability of the students improve and broad. Through the experimental teaching of virtual experiment, it greatly stimulates the students' interest in learning, enhances the interest and the effectiveness of the experiment, which is conducive to the students' personality development and the cultivation of creative ability and thinking ability. Meanwhile, the experimental teaching quality is improved obviously. Through many aspects of the teaching construction and reform, the teaching quality has been further improved, increasing the vitality of the course, and students reflect is good.

\section{Acknowledgement}

This work was supported by Course Construction on Introductory to Mechanical Engineering Projects Funded by Beijing Institute of Graphic Communication and by Fine Course Construction of Modern Design Theory and Method Projects of Beijing Institute of Graphic Communication.

\section{References}

[1] Xiao-gui Zhang, Development and Reform on Foundation of Mechanical Design for non-Mechanical Profession,The Conference on Higher Education Curriculum and Teaching Reform(HECTR 2012),July 6-7,2012,HECTR 2012:pp126 128.

[2] Xiaogui Zhang, Ziyuan Shi, Exploration in the Mechanical Design Curriculum and Teaching Based Cultivation of Engineering Capabilities 2012 2nd International Conference on Future Computers in Education (ICFCE 2012)June 1-2, 2012, Shanghai, China,ICFCE 2012:pp325 328.

[3] Xiaogui Zhang,Yi Chu,and Bo Gao, Creative Combination Simulation System Design of Mechanical Transmission Based on Image,Advanced Materials Research Vol.510(2012) pp 96-100. 